\title{
Las interrogantes que nos deja el Reglamento de Oferta Pública de Adquisiciones y Compra de Valores por Exclusión en un escenario de adquisición directa de participación significativa
}

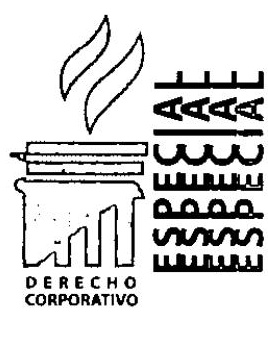

Ismael Noya de la Piedra

Abogado por la Pontificia Universidad Católica del Perú. Master en Derecho (MCJ) por New York University.

Yazmin Farah Manzur

Abogada por la Universidad de Lima. Master en Derecho (LL.M.) por New York University.

Egresada del Programa de Alta Especialización en Finanzas y Derecho Comercial (PAE) de ESAN.

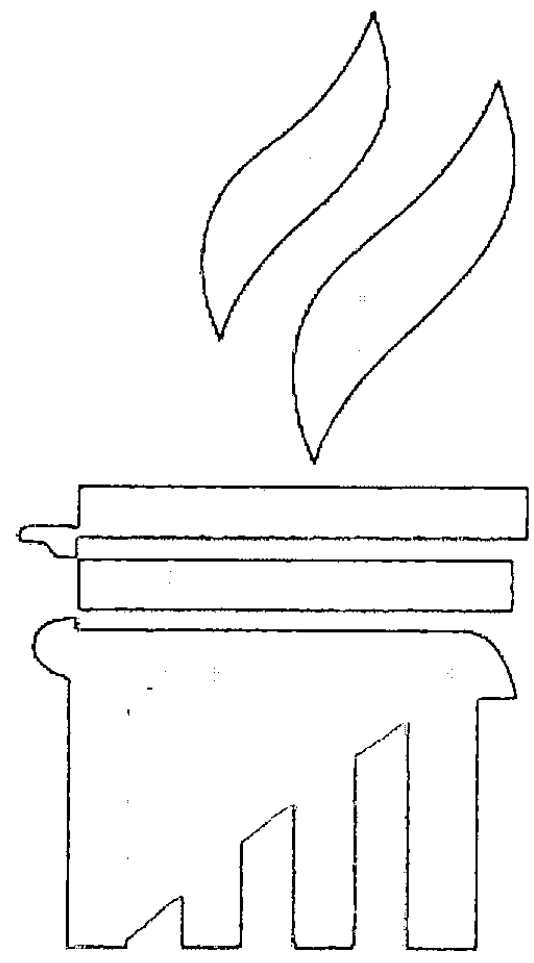

\section{INTRODUCCIÓN}

El actual Reglamento de Oferta Pública de Adquisición y Compra de Valores por Exclusión, aprobado por Resolución CONASEV No. 009-2006-EF-94.10 (el "Reglamento de OPA"), nos deja una serie de interrogantes o vacíos, respecto de ciertos temas frente a los cuales nos encontramos en una transferencia de control de una empresa cuyas acciones con derecho a voto se encuentran inscritas en el Registro de Valores de la Bolsa de Valores de Lima y en el Registro Público del Mercado de Valores de CONASEV. 
En el presente artículo esbozaremos dichas interrogantes o vacíos desde una perspectiva práctica y sugeriremos la forma en que deberían ser clarificados o interpretados.

\section{VENTAS SUCESIVAS Y LA OBLIGACIÓN DE LANZAR UNA OPA}

Cuando se adquiere o incrementa de manera directa la participación significativa', de quien ostenta tal participación significativa, existe la obligación legal para el adquirente de lanzar una oferta pública de adquisición ${ }^{2}$ (la "OPA") dirigida a todos los titulares de acciones con derecho a voto de la sociedad objetivo.

En ese caso la norma prevé dos supuestos, que la OPA se formule de manera previa a la adquisición o al incremento de participación significativa, en cuyo caso la OPA debe formularse sobre el número de valores que se pretende adquirir y el precio que determine el futuro adquirente o; que la OPA se formule en forma posterior a la adquisición o al incremento de participación significativa. En la práctica el segundo supuesto se viene dando con mayor frecuencia, es decir, primero se realiza la adquisición o el incremento de participación significativa de manera directa y luego el adquirente formula la OPA posterior o comúnmente denominada OPA de regularización.
En la OPA posterior, el precio mínimo a ser ofrecido debe ser determinado por una entidad valorizadora y el plazo para formular dicha OPA debe ser dentro de los cuatros meses desde que se genera la obligación para lanzar la OPA o dentro de los cinco días desde la emisión del informe de valorización, lo que ocurra primero, salvo motivos de fuerza mayor o caso fortuito. Asimismo, en este supuesto la OPA debe formularse sobre el porcentaje de valores que resulte de la aplicación de una fórmula señalada en el Reglamento de OPA. ${ }^{3}$

Ahora bien, cabe preguntarnos qué sucede si dentro del plazo de cuatro meses que contempla el Reglamento de OPA para la formulación de la OPA posterior, y en el supuesto que hasta ese momento no se cuente con el informe de valorización, el adquirente y obligado legal a formular la OPA, transfiere la participación significativa a un tercero al mismo precio por acción que fue pagado en la primera transacción, ¿acaso surge una nueva obligación de lanzar una segunda OPA a cargo de dicho tercero o se entiende que la obligación del adquirente inicial se traslada al tercero?

Definitivamente ante una situación como la presentada, el Reglamento de OPA no elimina la obligación de formular la OPA a cargo del

1 Participación Significativa: De conformidad con lo dispuesto en el artículo 1 inciso 16) del Reglamento de OPA, se considera participación significativa toda propiedad directa o indirecta de acciones con derecho a voto que represente un porcentaje igual o superior al veinticinco por ciento del capital social de una sociedad que tenga al menos una clase de acciones con derecho a voto representativas de su capital social inscritas en una bolsa. También se considera participación significativa la facultad que posee una persona o grupo de personas de, sin tener propiedad directa o indirecta, ejercer el derecho a voto de acciones con derecho a voto que represente un porcentaje igual o superior al veinticinco por ciento del capital social de una sociedad o, acarree que el adquirente alcance una cantidad de acciones o tenga la potestad de ejercer los derechos políticos de acciones, en una cantidad tal que en cualquiera de los dos últimos supuestos le permita: i) remover, o designar a la mayoría de los directores, ii) modificar los estatutos de la sociedad.

2 De conformidad con lo dispuesto en el artículo 68 de la Ley de Mercado de Valores "La persona natural o juridica que pretenda adquirir o incrementar, directa o indirectamente, en un solo acto o en actos sucesivos, participación significativa en una sociedad que tenga al menos una clase de acciones con derecho a voto inscrita en rueda de bolsa, debe efectuar una oferta pública de adquisición dirigida a los titulares de acciones con derecho a voto y de otros valores susceptibles de otorgar derecho a voto en dicha sociedad".

3 El objetivo de la fórmula es encontrar el porcentaje máximo de valores que todos los titulares de valores que no participaron en la "transacción previa" que generó la obligación de lanzar la OPA hubieran podido vender, si dicha "transacción previa" se hubiera realizado a prorrata. De este modo se asegura que los titulares de valores a los que se dirige la OPA tengan oportunidad de vender la misma cantidad máxima de valores, sea que la transacción se lleve a cabo de una OPA previa o a través de una OPA posterior. 
adquirente inicial, con lo cual podríamos llegar a la conclusión que, al amparo de la legislación actual, surgiría una nueva obligación de lanzar una segunda OPA a cargo de segundo adquirente. Esta situación resulta excesiva e ilógica por cuanto no se ha generado una prima adicional, se trata de una misma sociedad objetivo y de los mismos destinatarios de la OPA. Lo que viene sucediendo en la práctica es que en supuestos como los presentados, se solicite una excepción de OPA a fin de evitar que se realicen dos OPA innecesarias. De concederse la excepción de OPA al primer adquirente surge una interrogante vinculada al plazo que tendría el segundo adquirente para formular la OPA. ¿Se entiende que tiene hasta cuatro meses adicionales o se entiende que únicamente le correspondería el saldo del primer plazo de cuatro meses que tenía el primer adquirente? Consideramos que la solución que se dé debe conciliar los intereses de ambas partes, es decir, no debe dilatarse el plazo innecesariamente en detrimento de los destinatarios de la OPA ni debe concederse un plazo tan corto que en la práctica no sea posible para el segundo adquirente poder formular la OPA. Deben evitarse los supuesto extremos tales como (i) futuras ventas sucesivas, inclusive entre empresas de un mismo grupo económico, en las cuales se pretendan acoger al plazo de cuatros meses por cada'una de las transferencias de participación significativa, ya que en dicho supuesto los destinatarios de la OPA se verían claramente perjudicados; $O$ (ii) que el segundo adquirente adquiera del primer adquirente la participación significativa diez días antes del vencimiento del plazo de cuatro meses para formular la OPA y se pretenda concederle únicamente un plazo de diez días para formular la OPA, lo cual le haría impracticable cumplir con su obligación de lanzar la OPA.

No debemos olvidar que las OPAs tienen como propósito contribuir a que en las tomas de control, adquisiciones o incrementos de participación significativa de una sociedad cuyas acciones con derecho a voto se encuentren inscritas en bolsa, se garantice a todos los accionistas que puedan participar en la prima que con tal motivo se pueda ofrecer. Sin embargo consideramos innecesario que se imponga una doble obligación por cuanto entre la primera y la segunda transacción no se habría generado una prima adicional a ser distribuida entre los titulares de acciones con derecho a voto de la sociedad objetivo. En el supuesto en que en la segunda transacción se pague un precio superior por acción al pagado en la primera transacción, también resultaría lógico que el primer adquirente solicite la excepción de OPA y que la misma sea formulada por el segundo adquirente. En dicho supuesto resultaría razonable que el regulador conceda tal excepción, por cuanto la mayor prima se situaría en la OPA que lanzaría el segundo adquirente, haciendo que la primera OPA, por ofrecer un menor precio, carezca de interés.

\section{TRATO DIFERENCIADO Y DERECHO A PERCIBIR UN MAYOR VALOR}

En una adquisición directa de participación significativa, comprador y vendedor se pondrán de acuerdo sobre el precio por acción objeto de la transferencia. Como mencionamos en la Sección II del presente artículo, dicha transferencia de participación significativa gatillará una obligación legal de formular una OPA dirigida a todos los titulares de acciones con derecho a voto de la sociedad objetivo que no participaron en dicha transacción privada, la cual será realizada de manera posterior a la adquisición. Asimismo, el precio mínimo a ser ofrecido en la OPA posterior deberá ser determinado por una entidad valorizadora, para lo cual deberá determinar el valor de la contraprestación en las transacciones que generaron la obligación de efectuar la OPA. Asimismo, el precio mínimo en ningún caso podrá ser inferior al valor de la contraprestación en las transacciones que generaron la obligación de efectuar la OPA.

Como se podrá observar, la base del precio mínimo, es el valor de la contraprestación que se pagó en las transacciones que generaron la obligación de formular la OPA. Ello quiere decir que el precio mínimo determinado por la entidad valorizadora no podría ser inferior pero si podría ser superior a al contraprestación antes señalada.

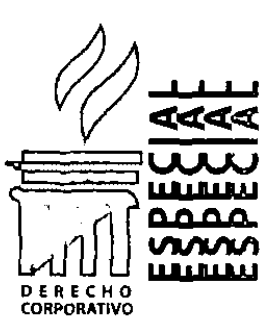

年 
Ahora bien, cabe preguntarnos, ¿acaso los vendedores que participaron en la primera transacción no tienen derecho a recibir el mayor valor que eventualmente la entidad valorizadora determine que corresponde ofrecer como precio mínimo a los destinatarios de la OPA posterior?

Dicha situación no se encuentra regulada en el actual Reglamento de OPA y, consideramos que podría generarse un trato diferenciado para los accionistas que vendieron en la primera transacción y para los que vendieron sus acciones en la OPA posterior, con lo cual se estaría vulnerando el Principio de Paridad de Trato. Recordemos que el Principio de Paridad de Trato lo que busca es que los accionistas que no participaron de la operación de venta que da origen a la OPA (también denominada como "transacción previa") reciban el mismo valor o precio que reciben los accionistas que son parte de la operación. No es el propósito buscado que reciban más que estos, lo cual sería un exceso. Claro está, que este tipo de situaciones no previstas podrían subsanarse regulándose en el contrato materia de la primera transacción, sin embargo consideramos que este tema podría incluirse también en el propio Reglamento de OPA a fin de clarificar interpretaciones contrarias sobre el tema.

\section{EL TRASLADO DE COSTOS AL COMPRADOR Y EL PRECIO}

Existe la posibilidad que, como parte de un proceso de venta de una sociedad con acciones inscritas en alguna bolsa, las partes acuerden que los costos que se generen como producto de la transacción y que correspondan al vendedor, sean traslados al comprador. Consideramos que claramente dichos costos trasladados, siempre y cuando cumplan con las características que señalaremos más adelante y que son costos justificables, no debería ser consideramos como parte del precio.

Sin embargo, ¿podría alguien preguntarse si al momento en que la entidad valorizadora prepare el informe de valorización para la determinación del precio mínimo a ser ofrecido en la OPA posterior debería considerar para la determinación de la contraprestación que se pagó en las transacciones que generaron la obligación de formular la OPA los costos que mediante el contrato de compraventa se trasladaron al comprador? La respuesta claramente es no, sin embargo, el actual Reglamento de OPA deja una ventana abierta para posibles interpretaciones ya sea del regulador o de la propia entidad valorizadora en sentido contrario. Consideramos que el traslado de costos por parte del vendedor al comprador no debería ser considerado como parte del precio y, en tal sentido, no deberían ser considerados para determinar la contraprestación en las transacciones que generaron la obligación de efectuar la OPA y que además constituyen la base del precio a ser ofrecido en la OPA posterior. Esto en razón de (i) que jurídicamente no son precio propiamente, y (ii) económicamente, evitar que se genere un trato diferenciado entre los accionistas vendedores y los accionistas que participaron en la OPA, al neutralizar que los accionistas vendedores carguen con los costos de la transacción que no serán compartidos con los demás accionistas que vendan sus acciones dentro del proceso de la OPA.

Cabe precisar que los costos que no deberían ser considerados como parte del precio son los relacionados estrictamente con la transacción. Dentro de ellos, por ejemplo, se encuentran los honorarios pagados a los banqueros de inversión, a los auditores, expertos técnicos y a los asesores legales que participaron en la transacción de compraventa, asi como cualquier otro gasto vinculado directamente al proceso de venta. Por el contrario, el precio por las acciones de la empresa debe estar vinculado estrictamente con los fundamentos de la misma. Todo aquello que sea ajeno a los fundamentos de la empresa y que constituya un gasto intrínseco a la transacción de compraventa debería ser excluido del precio.

Esta posición de ninguna manera puede ni debe de ser utilizada para disfrazar parte del precio como si fueran gastos y de esa manera reducir la base del precio mínimo que tendrá que ofrecer el adquirente a los destinatarios de OPA de regularización. Pero ello ya tendría que ser materia de un análisis caso por caso del gasto cuestionado. 